perhaps by limiting experiments involving the laboratory's smaller accelerators - until the project is reviewed in 1997, when final decisions on the timetable need to be made.

At present, however, neither Britain nor Germany seems willing to drop their demands for new voting procedures. And other countries are worried that this hard-line position could jeopardize the final agreement.

French officials, for example, say they will be looking at the two countries' proposals "with concern" as they want the LHC decision to be made with full assurances of financing. Italy is also worried. "We would regret seeing the buying power of CERN decrease," says Claudio Orsalesi, adviser to the Italian delegation.

Meanwhile, CERN's two host countries, Switzerland and France (the laboratory straddles the border between the two) have announced they are each prepared to accept another UK/German-led demand put forward last year, namely that they should make an increased payment towards the LHC in recognition of the benefits that CERN brings to their local communities.

Both countries say they will make a oneoff contribution after 1997 - either in cash or in kind. Switzerland will probably put forward a concrete proposal next week; the French government is still negotiating with the local authority where CERN is based to agree a sharing of cost. Alison Abbott

\section{IBM physicist picked for Trieste centre}

London. Praveen Chaudhari (below), a senior physicist at IBM's Thomas Watson Research Centre in Yorktown Heights, and a former head of the company's science programmes, has been chosen as the new director of the International Centre for Theoretical Physics in Trieste.

Chaudhari

has been with IBM since 1966.

He succeeds

Abdus Salam, who has been director of the centre - aimed in particular at providing training courses for physicists from developing countries - since 1964, and retired at the beginning of this year.

Chaudhari is the author of more than 150 technical papers, and is widely known for his work on electronic materials. He has been a senior advisor to both the US and Indian governments, and was chosen from a list of about 20 candidates by the governing council of the ICTP at a meeting held last week at the International Atomic Energy Agency in Vienna.

\title{
US physicists urged to build links with the modern world
}

San Francisco. A leading US physicist has warned his colleagues that the physical science community is seen as "non-cooperative with a new move to connect science more closely to the needs of society". In response, professional societies will be urged to endorse mission statements emphasizing their contribution to the "long-term opportunity for the nation".

Burt Richter, director of the Stanford Linear Research Center (SLAC) and president of the American Physical Society, told a forum of senior physical scientists earlier this month: "We are seen as recalcitrant, and wanting to go our own way."

In an attempt to correct this impression, the National Research Council (NRC) the research arm of the National Academy of Sciences - has embarked on an attempt forge a constructive response from the mathematical and physical sciences to their changing social environment. To start the process rolling, the NRC has sponsored a series of round-table meetings in Virginia, Colorado and California, aimed at hammering out a fresh justification for the American public's investment in the physical sciences to replace the old, unstated rationale of winning the Cold War.

At the Californian meeting, co-sponsored by Stanford University and held in San Francisco, senior academics in mathematics, physics and chemistry were invited to join the heads of government laboratories, Silicon Valley entrepreneurs and White House and congressional staff. Five important themes emerged from a weekend of discussion:

The physical sciences community is essentially inward-looking. Even its senior members are happier dealing with internal issues, such as course structure, rather than external ones, such as why the federal government should continue to pay its bills; - The community does face very real external threats, in particular the desire of its paymasters to 'pick winners' and to apply quantitative measures to the returns on investment in research investment;

- The community is sharply divided in its response. Some believe that the US research enterprise is so finely tuned that tampering with it can only do harm; others welcome the external pressure brought by the end of the Cold War as an overdue opportunity for radical change;

- Change, whether radical or gradual, will require physicists, chemists and mathematicians to work with other disciplines, including computer science, engineering and, in particular, the life sciences;

- Change will eventually take university teachers in mathematics, physics and chem- istry down the road already trodden by the engineering schools, towards more practical course content and industrial experience for postgraduate students.

But even senior faculty from élite schools represented at the meeting were at times uncomfortable discussing the big issues of science policy. A session on the "social contract" between science and society, for example, ended after two minutes when one speaker claimed that no such contract existed.

Bill Harris, head of mathematics and physical sciences at the National Science Foundation, identified one consequence of the community's isolationist tendency. "We sit on the sidelines of this process called democracy," he says. Such non-participation, others pointed out, can extend to the denigration of scientists who follow career paths outside academic institutions.

But outside pressures coming to bear on the physical sciences are not always obvious. MRC Greenwood of the White House science policy office warned, for example, that government performance law coming into force in 1997 will require federal agencies to formally assess programme outputs. "If the science community doesn't participate in developing appropriate assessments, it will become subject to measurements developed by or appropriate to other government activities," she says.

Richard Zare, the Stanford chemist who organized the meeting, favours a balanced response to all these pressures: "If we don't respond, we're dead; if we respond too much, we wreck the enterprise," he says. A rapid response is favoured by those in newer disciplines, such as computer science, who disliked the predominance of mathematics and physics in the old, Cold War system.

The Silicon Valley people at the meeting were generally happy with their current relationships with university science - and with the steady output of a postgraduate education system that they consider unequalled anywhere in the world.

But if the physical sciences have no trouble relating to industry, their relationship with a wider society is more fraught. In one attempt to reach out, Richter and Robert Byer, an applied physicist at Stanford who is president of the Optical Society of America, pledged to get the boards of their respective societies to consider mission statements.

One proposed wording is that "[the society] will focus its capabilities on teaching, research and scholarship to generate knowledge and long term opportunity for the nation". It sounds a small step, but it would be a big leap for scientists who tend to see their role as confined to the pursuit of pure knowledge.
Colin Macilwain 